\title{
Serpentine movement of filaria in wet mount preparation: aspirated from breast swelling
}

\begin{abstract}
Filariasis is a major health problem in tropical countries including India. Fine needle aspiration cytology plays an important role in prompt recognition of disease. Extranodalfilariasis is a rare entity, and the breast is also one of the sites for filariasis. Here, we present one case of filarial breast swelling diagnose by fine needle aspiration cytology in wet mount preparation. FNA is very effective diagnostic tool in the diagnosis of filarial breast lesion.
\end{abstract}

Keywords: breast swelling, fine needle aspiration, fna, wet mount preparation, filaria
Volume 3 Issue I - 2018

\section{Mani Krishna}

Department of Pathology, Uttar Pradesh University of Medical

Sciences, India

Correspondence: Mani Krishna, Associate Professor,

Department of Pathology, Uttar Pradesh University of Medical Sciences, Saifai Etawah 20630I, Uttar Pradesh, India, Email drmanikrishna@gmail.com

Received: November 02, 2017 | Published: January 30, 2018

\section{Introduction}

Filariasis is a common health problem in India and South East Asia. Heavily infected states in India are Utter Pradesh, Bihar, Jharkhand, Andhra Pradesh, Orissa, Tamil Nadu, Kerala and Gujrat. About $95 \%$ of cases of lymphatic filariasis are caused by infectious of Wuchereria bancrofti in world followed by Brugia malayi and Brugia timori. ${ }^{1}$ In India most of the disease is caused by two nematodes $W$ bancrofti and B. Malayi. ${ }^{1}$ It is transmitted by the bite of mosquito. Adult worms are found in the lymphatic vessels and lymph nodes of man only. The embryos (Microfilaria) circulate in the peripheral blood and sucked up by their appropriate intermediate host (mosquito). It is quite unusual to find adult worm in breast aspirates. Definitive diagnosis of lymphatic filariasis depends upon the demonstration of living parasites in the human body by night blood survey. Fine needle aspiration (FNA) is the best diagnostic tool for evaluation of palpable breast swelling. Lymphatic filariasis and its severe manifestations are prevented by making an early diagnosis and early treatment can be instituted.

\section{Case report}

A 30 year - old female presented to pathology department for FNAC with a painless swelling in the right upper quadrant of the breast since 5year. The patient had no history of anorexia, weight loss or nipple discharge except off and on fever. General physical examination was unremarkable. On systemic examination, there was a single well defined, cystic, cord like swelling of size $0.5 \times 1.5 \mathrm{~cm}$ in upper outer quadrant of right breast. Patient routine haematological investigation including blood eosinophil count (4\%) and biochemical investigation were also within normal limits. Peripheral blood smear for microfilariae and filariasis $\mathrm{Ig} \mathrm{G} / \mathrm{Ig} \mathrm{M}$ combo rapid test were negative. FNA was done by a $23 \mathrm{G}$ needle attached with $10 \mathrm{ml}$ syringe and yielded $1.5 \mathrm{ml}$ straw coloured fluid. The smears made were wet mount. The wet mount preparation and the smears made from the fluid were studied microscopically. The wet mount preparation showed many motile microfilariae and few red blood cells in the background. [Figure-A, B, C] She was treated with diethylcarbamazine [100 mg three times a day] for 21 days.
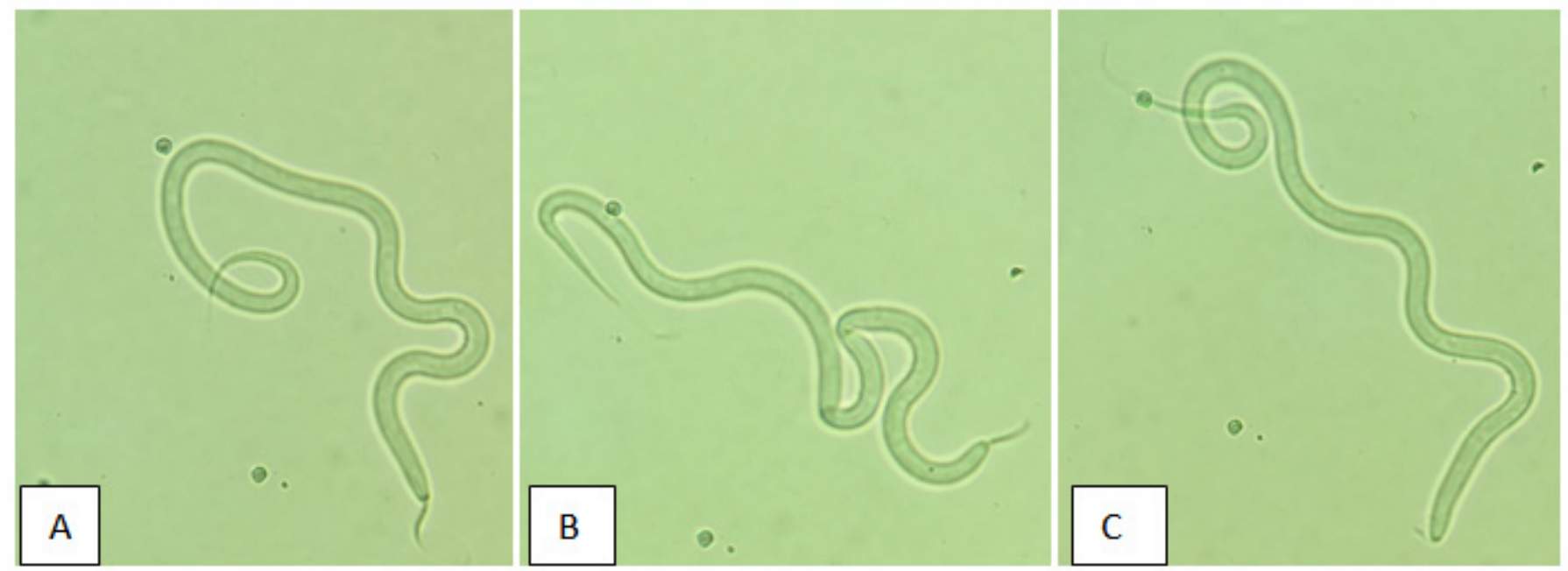

Figure IA-IC Photomicrograph of wet mount preparation of the fluid shows adult filaria 


\section{Discussion}

Filariasis is a major health problem of tropical countries like India. At least eight species of filarial parasites that cause human infections are Wuchereria Bancrofti, Brugia malayi, Brugia timori, Onchocerca Volvulus, Loa loa, Mansonella perstans, Mansonella Streptoceraca and Mansonella ozzardi. Among them lymphatic filariasis is caused by only three species i.e. Wuchereria Bancrofti, Brugia malayi, Brugia timori. About $95 \%$ of cases of lymphatic filariasis are caused by infection with $W$. Bancrofti. ${ }^{1}$ The parasite completes its life cycle in two hosts. Man is definitive host were sexual cycle takes place. Mosquito harbours the larval stage of parasite. Adult worms reside in the lymphatic channels and lymph nodes of man. Female worm are viviparous giving birth to approximately 50,000 microfilariae per day. ${ }^{2}$ Microfilariae completes its development in the mosquito, giving rise to the infective larva form. Infection is transmitted to definitive host by the bite of mosquito. Bancroftianfilariasis causes a wide range of clinical manifestations. In acute phase, presentation may be varied ranging from fever, lymphangitis, lymphadenitis and epididymo-orchitis. Chronic stage is characterized by lymphoedema, lymphadenopathy, hydrocele and elephantiasis. Majority of infected individuals are asymptomatic. ${ }^{3}$ In our case, microfilariae was not seen in the peripheral blood smear examination. Filariasis can manifests without microfilaremia or microfilaremia may be extremely transient. ${ }^{2}$

The most commonly affected lymphatics are those of lower limbs, spermatic cord, epididymis and retroperitoneal tissue. ${ }^{1}$ Breast filariasis is quiet unusual and commonly presents with a unilateral, painless, solitary palpable lump in the upper outer quadrant of breast. ${ }^{4}$ Walter et al suggested that microfilariae appears in tissue fluids and exfoliated surface material due to lymphatic and vascular obstruction and subsequent extravasation..$^{5}$ Diagnosis of filarial lesions depends upon the demonstration of microfilariae in the peripheral blood smears prepared from mid-night sample and detection of filarial antigen and antibody. Ultrasonography [USG] serves as a valuable diagnostic tool in cases of lymphatic filariasis. A specific movement of worms called as filarial dance has been described by USG. ${ }^{6}$ After a period of time these worms calcify and then imaging modalities findings are indistinguishable from intraductal carcinoma of breast. ${ }^{7}$ The role of FNA in the diagnosis of filariasis is well established and cost effective. The wet mount preparation revealed many motile adult filarial worm and few red blood cells in the background. In a study by Shaila et al., ${ }^{8}$ eight cases of breast filariasis were reported out of twenty four cases. ${ }^{8}$ The study done by Varghese et al reported only one case of microfilariae in cystic breast lesion out of six cases of microfilariae in cytological smears. ${ }^{9}$ Diethylcarbamazine is the drug of choice as it is effective against the adult worm and microfilariae.

\section{Conclusion}

As India is an endemic for filarial infection, it is necessary to examine carefully FNA wet mount preparation from breast swelling for filariasis. It helps clinician to reach early on the diagnosis of filarial infection and its treatment.

\section{Acknowledgements}

None.

\section{Conflict of interest}

The author declares no conflict of interest.

\section{References}

1. Park K. Park's Textbook of Preventive and Social Medicine. 21st ed. India: Bhanot Publishers; 2005. p. 211-216.

2. Chatterjee KD. Phyllum nemathelmenthes, classnematoda. In Parasitology (Protozoology \& Helminthology) in relation to Clinical Medicine. 12th ed. India: Med Publishers; 1980. p. 190-199.

3. Nutman TB, Kumaraswami V. Regulation of the immune responce in lymphatic filariasis: Perspectives on acute and chronic infection with Wuchereria bancrofti in South India. Parasite Immunol. 2001;23(7):389-399.

4. Upadhyaya V, Upadhyaya DN, Sarkar S. An interesting case of breast filariasis. Indian J Radiol imaging. 2006;16(4):915-917.

5. Walter A, Krishnaswami H, Cariappa A. Microfilariae of Wuchereria bancrofti in cytologic smears. Acta Cytol. 1983;27(4):432-436.

6. Mashankar A, Khopkar K, Parihar A, et al. Breast filariasis. Ind J RadiolImag. 2005;15(2):203-204.

7. Friedman PD, Kalisher L. Filariasis. Radiology. 2002;222:515-517.

8. Shaila KM, Rajiv KM, Pallavi V. Cytological diagnosis of microfilariae in filariasis endemic areas of eastern Uttar Pradesh. $J$ Cytol. 2009;26(1):11-14.

9. Verghese TR, Raghuveer CV, Pai MR, et al. Microfilariae in cytologic smears: A report of six cases. ActaCytol. 1996;40(2):299-301. 